slightly different; while the values for the elastic force of vapour have not been corrected for the assumed barometric pressure. Nevertheless, a decidedly rapid increase in the humidity of the atmosphere is shown, and in considering the table, it must be borne in mind that the results, if reduced to a mean temperature, would be even more striking.

Barnet, February 18. E. V. WINDSOR.

\section{Lagrange's Equations.}

As most of the standard treatises on dynamics contain satisfactory proofs of Lagrange's equations, I do not see that any useful purpose is served by proposing an additional one. The important point is this:-That amongst the rumerous forms in which the kinetic energy of a dynamical system can be expressed, there is only one form which can be employed in using Lagrange's equations, and that is the Lagrangian form in which $\mathrm{T}$ is expressed as an $n$-ary quadric of velocities which are the time variations of the coordinates.

Similarly in using Hamilton's equations

$$
\begin{aligned}
\frac{d \Theta}{d t}+\frac{\partial}{\partial \theta}(\pi+\mathrm{V}) & =0 \\
\frac{\partial \pi}{\partial \theta} & =\dot{\theta},
\end{aligned}
$$

there is only one form, viz. the Hamiltonian form, which it is permissible to use in which $\mathbb{C}$ is expressed as an $n$-ary quadric of momenta of the same type as the coordinates of the system. Now the form $\frac{1}{2}\left(\mathrm{~A} \omega_{1}^{2}+\mathrm{B}_{2}^{2}+\mathrm{C}_{3}^{2}\right)$ is neither Lagrangian nor Hamiltonian, and therefore cannot be used in either equations.

Fledborough Hall, Holyport, Berks, March 6 . A. B. BASSET.

\section{A Remarkable Meteor.}

I SEND an account of a meteor, to me remarkable because of its extremely slow movement and also because of its apparently reaching the surface of the earth, a little east of north-east of here. The "falling star "was about equal in brightness to Sirius. When first it attracted my attention it would be just below the cluster "Coma Berenices." So slowly was it falling that I first mistook it for the fixed star Arcturus, the resemblance being probably increased by its colour, which was reddish. It slowly dropped vertically downwards, its brilliancy keeping constant; it left no trail. Its line of descent would make a small angle with the line $\delta \beta$ Leonis. I watched it fall right to ground-but it may not have quite reached earth, as there was a rise in the ground before me. About one-third of its distance from the ground it appeared to "wobble, "but that may have been an illusion. It fell so slowly as to take quite five seconds. The time was about $7.22 \mathrm{p.m}$. on March 15 , when I was a little more than a mile to the south of Basingstoke.

J. E. C. LIDDLE.

Fairfields, Basingstoke, Hants.

\section{Dawn of Modern Geography.}

IN the review of my book ("Dawn of Modern Geography," vol. ii.) which appeared in NaTuRE, November 27 , 1902 , it is stated (p. 75), by way of repetition from NATURE's review of vol. $i$. of the same work, that the "revision of the whole of chapter vi. of vol. i., on geographical theory, together with Mr. Beazley's account of the history and use of mediæval maps for the whole book," was "due to $\mathrm{Mr}$. C. H. Coote, of the Map Department of the British Museum." When this unfounded assertion was first made, I wrote (with the entire concurrence of Mr. Coote) and pointed out to the reviewer that he was mistaken. As the misleading statement now reappears, I may say that $\mathrm{Mr}$. Coote never saw a line of the "Dawn of Modern Geography," vol. i.--nor had I any consultation with him on any point therein---until after the last corrections of proof had been made, and the sheets finallv returned for press.

C. RaymoNo BEazI.FX.

\section{Nernst Lamps in Lanterns.}

I T was suggested to me by a friend to use a Nernst lamp in a lantern. On trying the experiment I have found that a one ampere 220 volts Nernst lamp gives quite a fair result in a small lantern, certainly very much better than could be got with oil wicks, and when put at a small angle from the horizontal the filament gives a very concentrated light. For lantern purposes it would be quite possible to remove the heating coil and to start the lamp by means of an alcohol flame. Indeed, I think that a special Nernst burner could be made for lanterns, giving a high candle power and fitted with a suitable fitting, which would largely replace limelight, and it would even in many cases replace the are lamp where a powerful light was not required. There can be no doubt whatever about its convenience.

C. Turnbuli.

Electricity Works, North Shields, March 16

\section{PHOTOGRAPHS OF VOLCANIC PHENOMENA. ${ }^{1}$}

THE application of photagraphy to the recording and illustrating of volcanic phenomena has done much to secure accuracy, and the avoidance of those sources of error to which the students of these stupendous outbursts must always be particularly liable. Valuable as are the drawings made under the superintendence of Sir William Hamilton for his classic work, "Campi Phelgræi," they do not carry the conviction to the mind of a reader of the work that actual photographs would do; while many of the drawings of volcanic phenomena in less carefully illustrated works are faulty and exaggerated almost to grotesqueness.

Perhaps the first serious attempts to show the features of a volcanic outburst by means of instantaneous photography were those made by an enterprising photographer of Naples, during the Vesuvian eruption of 1872 . He obtained three photographs at different hours, which illustrate very clearly the scale, the principal details and the changes of phase in the outburst. These photographs have since been reproduced in many geological treatises.

During the visit of the Geologists' Association to the South Italian volcanoes in 1890 , a number of photographs were obtained by members of the party which demonstrated the value of instantaneous pho'ography in recording all the successive stages of an outburst. Some of these photographs were reproduced in a memoir published by Dr. Johnston Lavis at Naples in $\mathrm{r} 8 \mathrm{gr}$.

Dr. Tempest Anderson's contributions to the subject appear to have begun in $188_{5}$, when he read a paper, illustrated by admirable photographs, before the Geological Section of the British Association at Aberdeen. This paper dealt specially with the extinct volcanoes of Auvergne. In subsequent years, Dr. Tempest Anderson has visited almost all accessible volcanic districts--Italy and Sicily, the Canaries, Iceland, and various parts of the North American Continent. Last year he volunteered, at his own expense, to join the expedition sent out by the Royal Society to report on the eruptions of St. Vincent and Martinique, and the results obtained by Dr. Flett and himself have just been published in the Transactions of the Royal Society.

The work before us consists of reproductions by

1 "Volcanic Studies in Manv Lands: heing Reproductions of Photographs by the Author of above One Hundred Actual Objects, with Explanatory Notices." By Jempest Anderson, M.D., B.Sc. Lond. Y orkshire philosophical Societv (London: John Murray, rgo3.) Price 2is. net. 